\title{
The Development of Chinese Piano Music
}

\author{
Le Kang \\ University of Colorado at Boulder \\ Lian Hua 2 Cun 10-302, Shenzhen 518035, Guangdong Province, China \\ E-mail: lekang@hotmail.com, lekang20002000@yahoo.com
}

\begin{abstract}
Many Chinese pianists, Lang Lang and Yun-di Li for example, received international recognition in recent years. When study the history of piano study and composing in China, it is not surprising that the history of Chinese piano music has gone through specific periods which strongly influenced compositional activities. This article is aimed to display cultural and political aspects that are behind historical period and analyses representative work in compositional style and characteristics.
\end{abstract}

Keywords: Piano music, Chinese music, Development, History

\section{Introduction}

Historically, piano music has belonged to the West, especially the European piano pieces that have for years been considered standard piano repertoire. However, as the piano and its music have become popularized all over the world, piano repertoire has expanded to include not only European works, but also pieces by American, Latin American, and Asian composers. After the piano was introduced in China in the seventeenth century, quite a few pieces were composed specifically for the new instrument. Although this Chinese piano music is performed widely in China, it remains foreign to Westerners and their concept of "standard repertoire." Few pianists, even Chinese pianists, perform Chinese piano music outside of China. As communication and economic exchange between the East and West become more developed, people from both hemispheres want to learn more about each other. Despite the aspirations of both cultures to learn from one another, there is at times a lack of understanding and appreciation for cultural differences. This research aims to introduce some aspects of Chinese culture through the development of its piano music and to share the beauty of Chinese music.

Even though the history of the piano in China does not begin until the early twentieth century, the introduction of the keyboard instrument to China can be traced back to the 1600s. This paper discusses development of Chinese piano music in four major periods:

1. Before the People's Republic of China (Qing Dynasty to 1949)

2. New China Period (1949-1966)

3. Cultural Revolution (1966-1976)

4. Post Revolutionary (1976 to Present)

\section{Before the People's Republic of China (Qing Dynasty to 1949)}

In the seventeenth century, China was under the power of the Qing Dynasty. During the years of Emperor Kang Xi, commercial and religious contacts between the West and China developed quickly. The Emperor was interested in new things, especially poetry and music. In 1601, Father Matteo Ricci (1552-1601) brought the first Western instrument-a harpsichord - to China as a gift to the Emperor. This was the first Western instrument ever introduced to China.

Although Western music was well received in the Chinese court, it did not influence the ordinary people, who did not have access to the court. Also, because of wars between China and Western powers during the eighteenth and early nineteenth centuries, everything related to the West was rejected in Chinese society. As a result, the harpsichord remained only as part of the Emperor's collection; eventually, it was damaged and lost during the war years of the nineteenth century.

In 1840, China was defeated by England in the Opium War and was forced to open the coastal cities to Western powers. 
After the defeat, the West increased its influence over the Chinese economy and political landscape. In 1850, a British man opened the first piano shop in Shanghai. (Note 1) During this time, Western missionaries became more active in Chinese society as well. The missionaries brought not only medical and educational services to China, but also Western piano music. Many churches were established, and harmoniums were widely used in religious services. Church-sponsored schools offered elementary music study as well as piano lessons. Later on, the American-manufactured reed organ became a popular instrument because of its portability and economy. (Note 2)

The revolution of 1911, led by Sun, Yi-xian, ended the Qing Dynasty. As a physician educated in Japan and the United States, Dr. Sun, who established the Republic of China, tried to replicate the democracy and modernization that he had experienced in the West. As a result, Western political ideas, including science, education, literature and arts, were introduced to China at astonishing rates. In the first decade of the twentieth century, a great number of Chinese students went abroad to study. Japan became the first choice for many Chinese students, because of its close proximity. It was also in Japan where Chinese students encountered Western music and instruments. First-hand knowledge of Western music, harmonium and piano was brought back to China, as the students returned. Thousands of harmonium pieces such as Pieces for Harmonium (1908) and A Method of Harmonium Playing (1911) were published in the first two decades of the twentieth century in China. (Note 3)

During the twentieth century the piano gradually gained more popularity and became a major musical instrument in China. Some of the schools that offered piano lessons at that time included: McTyeire School for Girls, Shanghai, established in 1883; Hu Jun School for Girls, Hu-zhou, established in 1909; Jing hai Girls' School, Su-zhou, established in 1917; and Hui Wen Middle School, Nanjin, established in 1922. (Note 4)

As the popularity of the piano increased, traditional Chinese social values began to shift. During this time, girls were sent to study piano and were not considered educated if they could not play. (Note 5) Moreover, it was easier for musically educated girls to be accepted into high class society.

As the influence of Western musical culture continued to develop in China, the United States and European countries became popular destinations for study. Many Chinese people who looked to enhance their studies went to Europe and the United States between the years 1900 and 1924. Although most of them chose science as their major, a few studied Western music. Most students majoring in piano went to music schools in the Eastern part of the United States (such as New England Conservatory). Among this first generation of musicians who studied abroad, one student stood out in Chinese music history: Dr. Xiao, Yong-mei (1884-1940), who was also known as the "father of modern music education in China." (Note 6) Dr. Xiao studied piano, voice and music education in Japan from 1910 to 1919. He also studied music theory at Leipzig University and piano and composition at the Leipzig Conservatory of Music, Germany. Dr. Xiao was the first Chinese musician to earn a Ph.D. (1916) from the West. While studying in the West, Dr. Xiao observed the development and importance of keyboard instruments in the Western process. (Note 7) He felt that Western music and its educational system were more advanced, so he decided to devote himself to improving music education in China.

After establishing music departments in several universities in Beijing, Dr. Xiao finally got a permit from the government that allowed him to establish a national music institute. This institute, called the National Conservatory of Music, was founded in Shanghai on November 27, 1927 and became the first institute in China to provide professional music education at the collegiate level. Instrumental study was limited to piano, violin, cello, and traditional Chinese instruments. Performance on all instruments was highly emphasized. Other courses offered included Western music history, theory, harmony, counterpoint, orchestration, musical forms, music literature, and appreciation. (Note 8)

During the late 1920s and 1930s, the rapidly growing economy in the coastal cities made Shanghai a center of trade, banking, and industry in the Far East. Many Westerners moved to Shanghai, including outstanding Russian musicians trying to escape from the Russian Revolution and Jewish musicians trying to escape from Nazi persecution in Europe. (Note 9) This provided Dr. Xiao, who was the Dean of the National Conservatory at that time, an opportunity to recruit the best musicians available for faculty positions. By the early 1930s, eight out of a total of forty-one faculty members in the Conservatory were Europeans. The rest were Chinese who had studied in the West. (Note 10) Many musicians who served on the piano faculty were Russian pianists from the St. Petersburg Conservatory and the Moscow Conservatory, including Mrs. E. Levitin, Z. Pribitkova, B. Lazareff, and Alexander Tcherepnin. The most influential member of the piano faculty was Boris Zakharoff (from the St. Petersburg Conservatory), who headed the department. As a student of Leopold Godowsky in Berlin, Zakharoff was an excellent pianist who concertized during the Russian revolution and eventually settled in Shanghai. From 1929 until he died in 1942, he devoted his life to training Chinese pianists.

Other Western musicians who worked at the Conservatory included pianist Ada Bronstein of Germany; famous Jewish violinist and piano pedagogue Alfred Wittenburg; and conductor of the Shanghai Municipal Orchestra Mario Paci from Italy. (Note 11) With the establishment of the National Conservatory and the training available from the excellent faculty, Western piano repertoire flourished in China. Many Chinese pianists who graduated from the Conservatory 
either became concert performers or distinguished teachers at the Conservatory. Thus, these teachers established a tradition of their own in piano pedagogy, a heritage that has continued to this day. With this system, the faculty was appointed to teach different levels of students from primary school to college, with well designed repertoire for each level based on technique and musicianship training. For these reasons, the National Conservatory could be considered "the cradle of Chinese piano music." (Note 12)

Even though many Chinese people were educated in the West, piano music was not as widely known in China as it was in the West. After studying in the West, Chinese musicians felt it was important to introduce piano music to the Chinese people. In order to attract an appreciation from Chinese audiences, musicians began to experiment with new compositional techniques that combined Western harmony, counterpoint, and structures with distinguished Chinese characters. (Note 13) Traditional Chinese compositions were usually written on the pentatonic scale, the seven-tone scale, or the twelve-note scale. Among these, pentatonic modes were the most popular. Five essential modes were used in the pentatonic system (See example 1 on page 9). The scale consisted of whole tones, a minor third and a major third, avoiding half steps. (Note 14) Harmonic writing was not found in traditional Chinese music; thus, combining Western harmony with Chinese modes challenged Chinese composers.

\section{Insert Example 1 about here}

Composers such as Xiao, You-mei (1884-1940), Zhao, Yuan-ren (1892-1982) and Huang, Zi (1904-1938), became pioneers of these compositional experiments. Music such as Xiao's piano suite Xin Ni Shang Yu Yi Qu, Op. 39, composed in the 1920s, resulted from these experiments. Inspired by an ancient court dance of the Tang Dynasty described by Poet Po, Chu-i (772-846 A.D.), the piano suite consists of an introduction, twelve dances and a coda. (Note 15)The piece uses a pentatonic scale as the melodic line, accompanied by Western style major and minor triads, octaves, and fifths.

Dr. Zhao, Yuan-ren, who also experimented with Chinese piano music around the same time, pointed out in his article in 1928 the importance of using counterpoint along with the pentatonic scale. He suggested, "It is better to use all twelve tones and occasionally use pentatonic chords to achieve Chinese flavor." (Note 16) This laid a foundation for Chinese composers who wanted to create piano music with both Western harmony and Chinese character.

Another composer who largely influenced Chinese piano composition was Huang, Zi. After graduating from Yale in 1929, Huang, Zi became chair of the composition department at the National Conservatory. He taught almost every course in the department and encouraged students to understand Chinese tradition and spirit. By doing so, they could create Chinese music with both Western compositional techniques and traditional elements, instead of simply copying the Western music pattern. (Note 17)

There were also some Westerners who supported the creation of new Chinese music. In 1934, Russian composer and pianist Alexander Tcherepnin came to Shanghai from Paris as a consultant to the Ministry of Education. In order to encourage the development of new Chinese music, Tcherepnin organized a competition for piano compositions that used both Western and Chinese styles.

First-prize winner of the first Tcherepnin competition was He, Lu-ding, born in 1903 in Shao Yang, Hu-nan province. In his youth, he studied bamboo flute and other Chinese instruments, harmonium, music theory, and piano on his own. In 1931, he enrolled in the National Conservatory in Shanghai and studied with Professor Huang, Zi. In 1949, He, Lu-ding was appointed president of the Shanghai Conservatory, a position which he held until his retirement in the 1980s. During the 1930s and 40s, He, Lu-ding wrote film music, patriotic and popular songs, piano music and works for orchestra. Two of his piano pieces submitted to the Tcherepnin competition, Short Flute of the Shepherd Boy and Berceuse, won top prizes. Chinese-flavored melodies were always found in He, Lu-ding's music. For instance, Short Flute of the Shepherd Boy, was simple and pastoral, with tunes reminiscent of the bamboo flute. The inspiration for this piece was a picture of a shepherd boy playing the bamboo flute on the back of a water buffalo on a sunny day. The music was light and relaxing, full of joy and peace just like the picture that inspired it (See appendix A).

This piece is written in simple ternary form and the pentatonic mode of Zhi (tonic in G) is used with Western counterpoint in the first section, in which the left hand supports and responds to the melody (See example 2 on page 12).

\section{Insert Example 2 about here}

Mode Zhi (see Example 1 on p.9) shifts to mode Gong (tonic in G) in the B section with F-sharp as a passing tone. Mordents are used to imitate the double-tonguing techniques of the bamboo flute, while the left hand plays a dance rhythm in 2/4 (See example 3).

\section{Insert Example 3 about here}

A typical device of ornamentation popularly used in Cantonese music of South China called "JiaHua" is adopted in the A' section. The direct translation of "JiaHua" in English is "adding fancy," indicating the addition of notes as 
ornamentation or decoration to the melodic line while keeping the original shape (See example 4a, 4b). (Note 18)

\section{Insert Example 4a about here}

\section{Insert Example 4b about here}

Short Flute of the Shepherd Boy shows He, Lu-ding's talent for combining Western compositional technique with Chinese folk tunes. It was premiered by He, Lu-ding himself on the seventh anniversary of the founding of the National Conservatory and was the first Chinese piano piece to be recorded on a gramophone. He, Lu-ding believed that "only when music is written in the nationalistic style, can it be appreciated and recognized by the people of the world." (Note 19) This was an important concept, because it led the way for Chinese music to be presented and recognized by the world. The success of Short Flute of the Shepherd Boy increased the popularity of piano music in China, and it became a monument in the development of Chinese piano music, providing a model for Chinese composers to create piano music that belonged to their own culture.

\section{New China Period (1949-1966)}

After the foundation of the People's Republic of China in 1949, new conservatories were established in addition to the National Conservatory. Faculty in those conservatories included Western-educated musicians from the Soviet Union, Europe, and China. In order to promote education, the government also sent some composers to study in the Soviet Union, because of the strong relationship between the Russian and Chinese Communist Parties. (Note 20) Compared to the turbulent years of the early twentieth century, this was a peaceful period for living and producing music. Composers were allowed to express themselves freely, which resulted in compositions of various styles of piano works, such as Three Preludes (1954) by Sang, Tong and Etudes (1955) by Du, Ming-xin. It was the first time that Chinese composers expanded upon Western music styles by incorporating Chinese musical language.

Another experimental period came in 1957, when Chairman Mao released his new policy for music and art. He indicated that China should "make the past serve the present and Western things serve China." (Note 21)Chinese composers tried even harder to adapt Western harmonies, forms, and genres, while preserving Chinese musical language. An example is the Mermaid Suite by Du, Ming-xin and Wu, Zu-qiang. Both Du, Ming-xin (1928-) and Wu, Zu-qiang (1927-) had studied composition and theory in the Tchaikovsky Conservatory between 1952 and 1957. Du was appointed Chair of the composition department of the Central Conservatory in Beijing, and Wu was appointed as President of the Central Conservatory, a position he held until 1989. Du, Ming-xin's compositions included three symphonies, two ballets and some piano music. (Note 22) $\mathrm{Wu}$, Zu-qiang's compositions included solo piano music, cantatas and concerto for traditional Chinese string instruments, erhu and pipa. (Note 23)

The Mermaid Suite is a piano arrangement from 1959 that was influenced by impressionism. It was originally composed for a ballet based on a love story between a mermaid and a young hunter.

There are eight pieces in the piano arrangement, the most popular of which is Seaweed Dance (movement three). The introduction of this three-part piece makes use of impressionistic harmonic progressions that describe the calm surface of the sea (See example 5).

\section{Insert Example 5 about here}

Two traditional Chinese pentatonic scales are used in this piece. The main theme appears in section A and is based on Chinese folk-song style, in Gong mode (tonic on B). The main theme appears four times with variants and dynamic changes each time. The key modulates from B major in the first appearance of theme to $G$ major in its second appearance. (Note 24) This harmonic color change, not used in traditional Chinese music, is primarily adopted from the West.

The mode changes from Gong (Example 1) to mode Yu in section B, tonic on $b$ (minor) with quasi-canonic texture (Example 6).

\section{Insert Example 6 about here}

This device may be influenced by pipa technique. The pipa is a four-stringed plucked instrument originally plucked by thumb and second finger to alternate playing on a single string or different strings. (Note 25) The Mermaid Suite was considered the first mature piano piece to combine Western harmonic progressions and Chinese musical language. (Note 26)

\section{The Cultural Revolution (1966-1976)}

During the Cultural Revolution (1966-1976), all forms of art related to Western culture were forbidden by the government. At this time the political environment changed in China. The government, shifting away from Western ideas and values, stated that no Chinese would be allowed to teach or learn Western music or instruments. Training institutes were closed and the Ministry of Culture was disbanded. Everything related to the West was considered bourgeois and was punishable in China. All pianos were either sealed or destroyed by the Red Guards. During the ten 
years of the Cultural Revolution, only eight Revolutionary Model Works were approved to be performed. (Note 27) Six of the eight works were modified Beijing operas, and the other two were ballets. All of these works contained strong political content designed to praise Chairman Mao, the Communist Party, or the Chinese army and the victory of civil revolution. Other musical activities were also stopped at this time, and new musical compositions were not allowed to be created, unless they served a political purpose. Only piano music commissioned by the Chinese government was allowed. In compliance with government restrictions, and so they could continue to work, Chinese composers created piano arrangements from traditional Chinese music instead of creating new compositions.

One of the most important piano arrangements of this period was the piano concerto Yellow River (1969), arranged from a Chinese cantata by Xian, Xin-hai. The cantata describes the heroism and indomitable spirit of the Chinese nation during the War of Resistance against Japan, which was led by Chairman Mao. As a result, the piano concerto was widely accepted by the Communist party, even though Western classicism and romanticism were added in sections of the concerto. The premiere of Yellow River in 1970 was a huge success, creating a new model for making foreign things serve China. Still today, the Yellow River concerto is among the most important works of Chinese piano music.

With the success of this piano concerto, other piano music transposed from traditional instrumental music appeared during this period. Twin Butterflies by Chen, Pei-xun and Xiao Gu at Sunset by Li, Ying-hai, were among the most famous piano arrangements from this time. Twin Butterfly was originally Cantonese instrumental music and Xiao Gu at Sunset was from string and bamboo music.

Chinese music can be divided into three categories: Cantonese instrumental music (Guangdong province), String and Bamboo music (South Yangzi River), and Gong and Drum percussion ensemble (Chao Shan area). Cantonese music began in the Pearl River area, which includes Guangdong and Guangxi provinces, where Cantonese is the native dialect. This genre of music first appeared at the end of the Qing Dynasty, and at that time most of the music was inspired by Cantonese folk tunes and instrumental preludes. Even though Cantonese music started in the provinces, it soon spread to other big cities in China, including Shanghai, Tianjin and Beijing. Cantonese people were open to new things in general, and in their music. They honored folk tunes from all over China and included Western musical instruments to make up new ensemble arrangements. As a result, by adapting and combining all these elements, Cantonese music became a unique and distinct music style. Most Cantonese music was written with a seven-tone scale. Early orchestrations usually called for five instruments: erxuan, tiqing, san-xuan, yue-qing, and heng-xiao; such ensembles were called Wu Jia Tou (five-instrument group). In 1926, musician Lu, Wen-cheng extracted the erhu from Shanghai's String and Bamboo music, qin-qing from Chao Shan music and yang-qing from Cantonese music, shifting the ensemble group from five instruments to just three. He called the new ensemble San Jian Tou (three-instrument group).Later, Lu, Wen-cheng added the dong-xiao and the ye-hu to the ensemble, bringing the total back to five again. These two ensemble orchestrations are still used in Cantonese music today. Cantonese music is lively and energetic. Contrary to popular belief, with the exception of a few pieces, most of the music is lyrical and focuses on expressing the natural beauty of flowers, birds and landscapes.

String and Bamboo music became popular in the Jiang Su and Zhe Jiang provinces, especially around Shanghai. To distinguish String and Bamboo music from this region, it was also called River-South String and Bamboo music. The ensemble consisted of at least one erhu and one di-zi (Chinese flute) and usually had three to five players, with a maximum of eight. String instruments included the pipa, yang-qing, erhu, and san-xuan. Bamboo instruments included the di-zi, xiao, and sheng. Percussion instruments included the drum, wooden fish, ban and others. Most of the String and Bamboo music was mostly pentatonic and arranged from various instrumental folk tunes. Performance styles varied, depending on locations. For performances outside, the style would be bold and unconstrained; for inside performances, it would be delicate, tasteful, and beautiful.

Chen, Pei-xun, composer of Twin Butterflies, was born in Hong Kong in 1921. He began studying piano and composition during his teenage years, and was accepted by the Shanghai National Conservatory to study composition and orchestration in 1939. After the establishment of New China in 1949, he served as chair of the composition department at the Central Conservatory. Chen, Pei-xun arranged five piano pieces based on Cantonese and folk music. Four out of the five were published in 1959, and the last one came out in 1978.

The arrangement of Twin Butterflies has two main themes. One is from a Cantonese folk tune of the same title, and the other, which appears in the second part of the arrangement, is from The Narcissus, another folk tune from the Jiangsu province. As shown below in example 7b, the tune of The Narcissus is used in the second part of the piece as theme and variations. It is titled "Twin," as the repetition of each few bars produces a "pair of" or "twin" phrases (See example 7a).

\section{Insert Example 7a about here}

\section{Insert Example 7b about here}

Li, Ying-hai, composer of Xiao Gu at Sunset, was born in 1927 in Sichuan. He began professional education in composition, piano, and harmony at Chong-qing National Conservatory of Music at the age of sixteen. Li admired 
Kodaly and Bartok for their nationalistic cause and decided to commit himself to the study of Chinese folk music while teaching at the Conservatory. (Note 28) Li, Ying-hai was the first Chinese musician to publish a book about Chinese music theory, Han Modes and Their Harmonization (1959), which described the system and theory of Chinese modal harmony. Another publication, Pentatonic Finger Exercises for Piano, was designed for systematic exercises of pentatonic scales for pianists. (Note 29) As he explained, the purpose of this work was "to help students to develop a habit of playing minor thirds in pentatonic scale, so that they can familiarize with the different patterns of Chinese pentatonic scales, modulations and some unusual patterns." (Note 30)

Xiao Gu at Sunset was originally a solo piece for pipa, date and composer unknown. Xiao Gu is an ancient musical genre from the Han Dynasty (140 B.C.) that features pipas and drums and is usually played outside. "Xiao" refers to a kind of Pipa, and "Gu" means drum. Examples of titles given to the original pipa solo piece were "Xun Yang Pipa" and "Moon night of Xun Yang." Scholars point out that "Xun Yang Pipa" may refer to the famous poem "Pipa Xing," by poet Bai, Juyi (Tang Dynasty). The poem describes meeting a pipa player whose sad fate reminded Bai of his own sad fate while on a boat in the Xun Yang River. The title "The Flowery Moon Night of Spring River" was given to the arrangement of this piece for the Chinese instrumental ensemble in 1925. The music describes a picture of boats sailing on the Yangzi River at sunset with a clear moon and a beautiful night scene along the river.

The piano arrangement calls for the piano to imitate different Chinese instruments that were used in the ensemble version. It consists of eleven sections, made up of free variations on a single theme. Different subtitles were given in the ancient score and subtitles written by Zheng, Jianwen were most commonly used for the piano arrangement. (Note 31) (See Appendix B)

Unlike Twin Butterflies which repeats each melodic line, phrases in this piece were connected by single notes (See example 8).

\section{Insert Example 8 about here}

The subtitle in each section presents a particular "picture." The Introduction starts in free tempo from a Chinese folk rhythm called San Ban. Here, the piano is used to imitate Chinese instruments used in the ensemble: the pipa and gu-zheng (See example 9 on p.25).The whole introduction illustrates a picture of boats returning on the Xun Yang River at sunset, while the sound of drum and Zhong drift from the shore.

\section{Insert Example 9 about here}

The Andante Moderato portrays a rising moon on the Xun Yang River, its reflection broken by paddling. The main theme in this section reflects an ancient Chinese poetic structure, Starting (beginning), Following (transforming), Turning (developing) and Combining (combination).

This theme re-appears in the Moderato, where thirty-second notes in the left hand imitate a picture of the shining reflection of water flowing with the breeze. Similarly, the Animando suggests a forest at the riverside, flowers reflected in the water. This beautiful section uses free rhythm and changes tempo from longer note durations to shorter ones (half note, quarter note, eight note, sixteenths, thirty-seconds).

The following section, Ad lib. Dolce-Piu-mosso-Sostenuto, recalls the timbre of the Guzheng by using a higher register in the piano to imitate overtones of string instruments. It represents a picture of floating cloud layers reflecting on the shining water. In the Lento-Moderato, seconds and thirds are used to imitate the Wooden Fish, an instrument that is used both for music and as a tool for reading Buddhist scripture. Both the Lento-Moderato and the following Allegretto describe a picture of singing fishermen on their boats during sunset. The last part of the section attempts to imitate the plucking of the guzheng.

"Sostenuto-Moderato," the title of the following part, indicates a changing tempo in this section. Tempo changes are used to portray the images of boats drifting closer and closer while fishermen are singing. The gestures of singing and boating are combined to begin the next section, Piu mosso-Stretto-Moderato. This section expresses the bravery and happiness of fishermen with fully loaded boats after a busy day. In these forty-eight measures, the tempo changes three times, leading to the climax (See example 10).

\section{Insert Example 10a about here}

\section{Insert Example 10b about here}

\section{Insert Example 10c about here}

\section{Insert Example 11 about here}

The coda, echoing the beginning, portrays the image of disappearing boats, as sounds of peace and calm return to the Xun Yang River.

The beauty of this piano arrangement and the successful use of the piano to imitate Chinese instruments make Xiao Gu at Sunset one of the most famous and popular pieces in the Chinese piano repertoire. It is also an excellent example of 
combining folk music with Western compositional techniques.

\section{Post Revolution (1976 to Present)}

The Cultural Revolution ended with the death of Chairman Mao, Ze-dong in 1976. Many of the restrictions on art and music that were instituted during the Cultural Revolution were eased, and the political tension between China and the West decreased. During this time composers regained the freedom to compose their own work without fear of punishment from the government. Unfortunately, the far-reaching effects of the Cultural Revolution continued to influence the creation of new piano arrangements. Many compositions from 1976 continued to use Revolutionary movie music, Chinese instrumental music, and ancient court music as inspiration.

The real change started in 1978, when Deng, Xiao-ping became the Chairman of China. Having studied in France, Deng was open to Western ideas, which he thought should be useful to China. Indeed, he brought huge political and economic development to the country. His announcement of an "open door" policy was the foundation for modern China, which welcomed the exchange between Chinese and Western culture. This policy provided a free atmosphere for composers. (Note 32) After 1978, many young composers went to the United States and Europe for further study, and a number won international competitions and became famous figures. These included Tan, Dun; Zhou, Long; Chen, Yi; and Ye, Xiao-gang, who also became well-known in the West. Modern compositional techniques were used in their works, in combination with Chinese cultural or folk elements, to reflect characteristics of China and Chinese life. A large number of compositions in various styles were published from 1978 to the present. In 1987, the first "Shanghai International Music Competition for Compositions and Performances in Chinese Style" was held in Shanghai and included competitors from twelve countries and areas. All twelve winners displayed different compositional styles, including impressionism, twelve-tone, and virtuosity. One of these works was Combination of Long \& Short, by Quan, Ji Hao.

As professor of composition at the Central Conservatory, Quan has won many awards for his works. One of his frequently performed piano works, Combination of Long \& Short, was inspired by drum rhythms from the Chao Xian nation, one of the minorities in northernmost China, populated by people of Korean descent and sharing a heritage with North Korea. The people speak Korean and wear traditional Korean dress in their festivals.

Combination of Long \& Short is an original work based on a typical Chao Xian folk drum (long drum) rhythm. The typical basic rhythm, shown below, combines long and short values.

This is a contemporary work that combines folk rhythm with modern technique to create an atmosphere of happy festivity. In Chao Xian dance, the long drum is often featured in instrumental ensembles. It is hung in front of the chest; the right hand holds a bamboo stick, and the left hand is attached to the drum edge, while the thumb and the remaining four fingers tap on it.

The suite consists of three movements, each featuring a particular rhythm combined with modern pitches and harmonies to bring a "new sound" to the original rhythm. The central "grape chord," consisting of three minor seconds and a tritone, appears throughout the suite (Example 12). (Note 33)

\section{Insert Example 12 about here}

The first Movement, Deng De Kong, features a light "Long, Short," used at holiday and festival parties. This rhythm in the right hand, as shown above, rings with the major seventh to minor ninth of the "grape chord," to represent happiness at the festival.

The second movement, Jin Yang Zhao, is a free and slow "Long, Short" from ancient China. In recitative style, it expresses deep, calm emotion. Again, the "grape chord" is found in the melody, now varied and extended with an ostinato in the left hand (See example 13).

\section{Insert Example 13 about here}

The last movement, En Mao Li, is a vivid and warm "Long, Short" in 5/8 with shifting accents, creating a vertical complex rhythm to represent the exciting dance scene of the festival.

Composers have continued writing throughout the1990s and 2000s. Two important works from this time included Tai Ji, by Zhao, Xiao-sheng, and Tang Ren Shi Yi, by Xu, Zhen-min. The former was inspired by Tai Chi, in which the composer, Zhao, Xiao-sheng, created a tai chi compositional system based on the sixty-four divine symbols in Tai Chi. The latter was commissioned by Barry Snyder at the Eastman School of Music in 1998, and was inspired by two ancient poems from the Tang Dynasty.

\section{Conclusion}

For a country with more than five thousand years of history, China has a record of piano music that is relatively short and largely influenced by political phenomena. Musical creativity was controlled by political oppression and later freed by open policies. After many years of trying, Chinese composers have finally moved on from simply imitating Western musical language and creating folk arrangements. Now, they have found their own way of making original 
compositions by using Western compositional techniques coupled with Chinese folk tunes and rhythms. In this way, they are creating pure Chinese piano pieces that express the beauty of Chinese music from ancient times to the present, while preserving cultural heritage through music. Although there is no unique style or direction, this change has already opened a door to future compositional creativity in China.

\section{References}

\section{Books}

Li, Xi-an, \& Jun, Chi. (1985). Chinese Folk Musical Forms. Beijing : People's Music Press.

Qian, Renping. (2005). Chinese New Music. Shanghai: Shanghai Conservatory of Music Press.

Wang, Yuhe. (1988). Chinese Contemporary Music History. Beijing: People's Music Press.

Yuan, Jingfang. (2004). National Instrumental Music. Beijing: People's Music Press.

\section{Articles}

Guan, Jiahua. (1997). Pursuing New Tone Color. Beijing: Piano Artistry, No. 1, 13-14.

He, Li. (1994). Piano Music by Li, Yinghai. Beijing: Piano Artistry, 8.

Huang, Zi. (1984). How to Create Chinese New Music. Art of Music, No. 4, 4-15.

Li, Yinghai. (1966). Pentatonic Exercises for the Piano. Shanghai: Culture Publishing House, 3.

Shao, Hua \& Guong, Li. (2001). A Brief Analysis of the Piano Piece 'Instrumental Music at Sunset. Beijing: Piano Artistry, No. 41, 25-26.

Zheng, Xue. (1998). Reminiscences of the McTyeire School. Selected Historical Recollections of Shanghai, series No 59. Shanghai: People's Publishing House, 306-7.

\section{Dissertations}

Bian, Meng. (1994). Forming and Development of Chinese Piano Culture. Beijing: Huayue Publisher.

Chen, Yuchien. (1988). A Short History of Chinese Music for Piano. DMA diss., Florida State University.

Hu, Hsinli. (1994). A Study of Chinese and Western Influences in Selected Pieces of Chinese Piano Music. DMA diss., University of South Carolina.

Wang, Rongshen. (1995). A Study of Five Chinese Piano Pieces with a Review of the Introduction and Development of the Piano in China. DMA diss., Ball State University5.

Zhang, Shigu. (1993). Chinese and Western Influences Upon Piano Music in China. DMA diss., University of Arizona.

\section{Notes}

Note 1. Chen, Yu-chien. “A Short History of Chinese Music for Piano.” (DMA diss., Florida State University, 1988), 1.

Note 2. Wang, Rong-shen, "A Study of Five Chinese Piano Piece with a Review of the Introduction and Development of The Piano in China." (DMA diss., Ball State University, 1995), 23.

Note 3. Ibid., 24.

Note 4. Ibid., 26.

Note 5. Zheng, Xue, "Reminiscences of the McTyeire School," (Selected Historical Recollections of Shanghai, series no. 59, People's Publishing House, Shanghai, 1988), 306-307.

Note 6. Ibid.

Note 7. Wang, Rong-shen, “A Study of Five Chinese Piano Piece with a Review of the Introduction and Development of The Piano in China." (DMA diss., Ball State University, 1995), 28.

Note 8. Ibid., 30.

Note 9. Ibid., 31.

Note 10. Ibid.

Note 11. Ibid.,33.

Note 12. Ibid.

Note 13.Ibid., 34.

Note 14. Ibid.

Note 15. Ibid., 35. 
Note 16. Ibid., 37.

Note 17. Huang, Zi, "How to Create Chinese New Music." Art of Music, no.4 (1984): 4-15

Note 18. Zhang, Shi-gu. "Chinese and Western Influences Upon Piano Music in China." (DMA diss., University of Arizona, 1993), 21.

Note 19. Wang, Rong Shen, "A Study of Five Chinese Piano Pieces with a Review of the Introduction and Development of the Piano in China." (DMA diss., Ball State University, 1995), 51.

Note 20. Wang, Rong Shen, "A Study of Five Chinese Piano Pieces with a Review of the Introduction and Development of the Piano in China." (DMA diss., Ball State University, 1995), 55.

Note 21. Zhang, Shi-gu. "Chinese and Western Influences Upon Piano Music in China." (DMA diss., University of Arizona, 1993), 30.

Note 22. Ibid., 32.

Note 23. Ibid., 31.

Note 24. Ibid., 33.

Note 25. Ibid,. 35 .

Note 26. Ibid., 35.

Note 27. Zhang, Shi-gu. "Chinese and Western Influences Upon Piano Music in China." (DMA diss., University of Arizona, 1993), 41.

Note 28. Wang, Rong-shen "A Study of Five Chinese Piano Piece with a Review of the Introduction and Development of The Piano in China." (DMA diss., Ball State University, 1995), 78.

Note 29. He, Li. Piano Music by Li Yanghai. Piano Artistry, Beijing. 1994, 8.

Note 30. Li, Ying-hai, Pentatonic Finger Exercises for the Piano, Culture Publishing House, Shanghai, 1996, 3.

Note 31. He, Li. Piano Music by Li Yanghai. Piano Artistry, Beijing. 1994, 8.

Note 32. Zheng, Shi-gu. "Chinese and Western Influences Upon Piano Music in China." (DMA diss., University of Arizona, 1993), 62.

Note 33. Qian, Ren-ping. “Chinese New Music.” Shanghai Conservatory of Music Press. Shanghai, 2005, 114. 


\section{Appendix A. A picture of Short Flute of the Shepherd Boy}

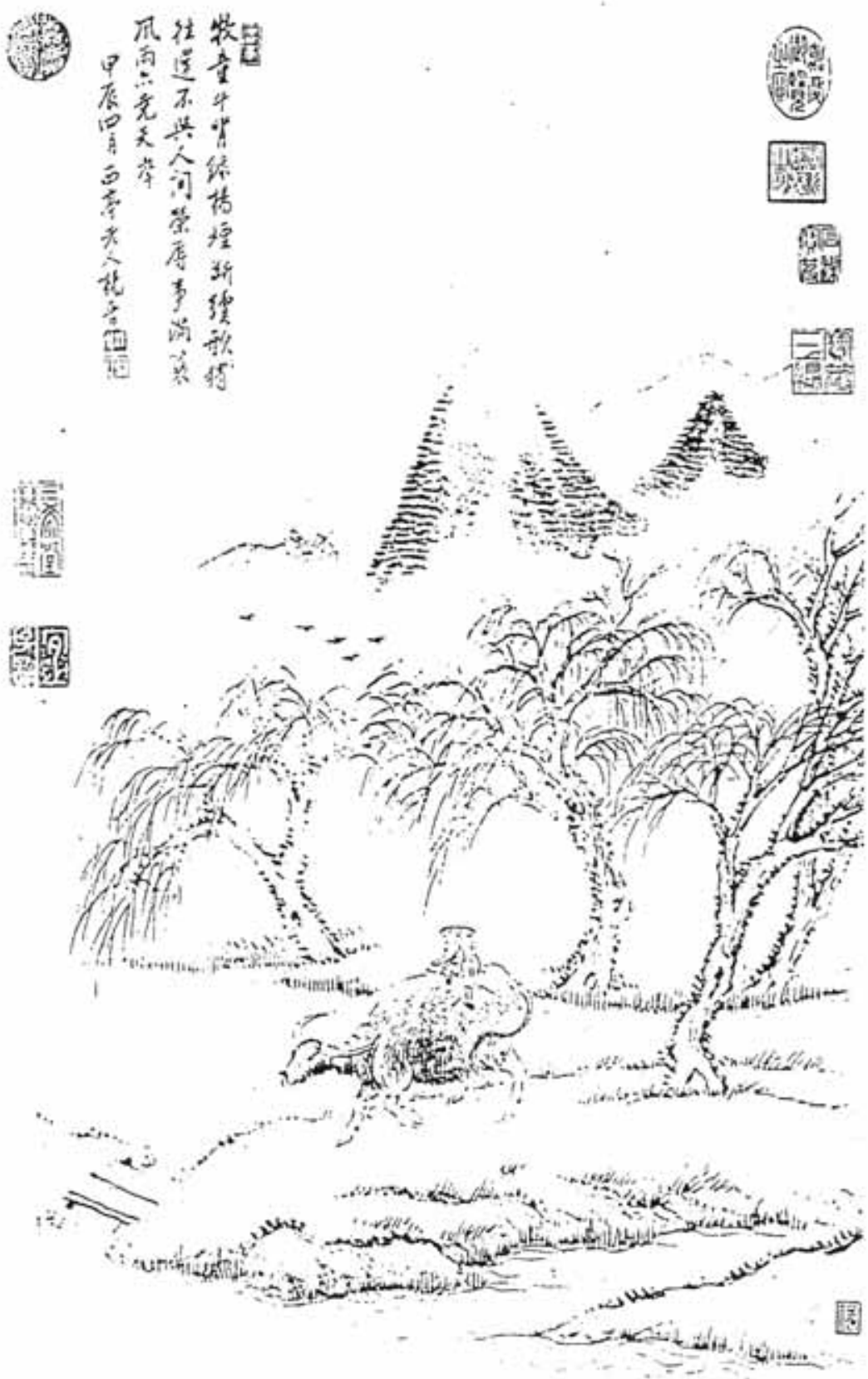




\section{Appendix B. Subtitles in Xiao Gu in Sunset}

Xiao Gu in Sunset

Measures
1-7 (introduction)
8-20(theme)
21-34 (var.I)
$35-56$ (var.II)

$57-70$ (var.III)

71-99(var.IV)

100-134(var.V)

135-154(var.VI)

155-192(var.VII)

193-253(var.VIII)

254-end (Coda)
Tempo Marking

Tempo a piacere

Andante Moderato

Moderato

Animando

Ad lib. Dolce-Piu

Mosso-Sostenuto

Lento-Moderato

Allegretto

Sostenuto-Moderato

Piu mosso-Stretto-Moderato

Sostenuto-Moderato-Presto

-Largamente-Moderato

Lento Ad lib. Tranquillo
Title

Intro:Xiao Gu at Sunset

Petals in the Breeze

Mountains Withholding the Moon

Setting Sun Over the Waters

Rustle of Autumn Maples

Towering Gorges

A Strain Flows Through

Reddening Leaves

Banks in the Twilight

Music From a Fishing Boat

Home-bound Boat Under Setting Sun

Coda

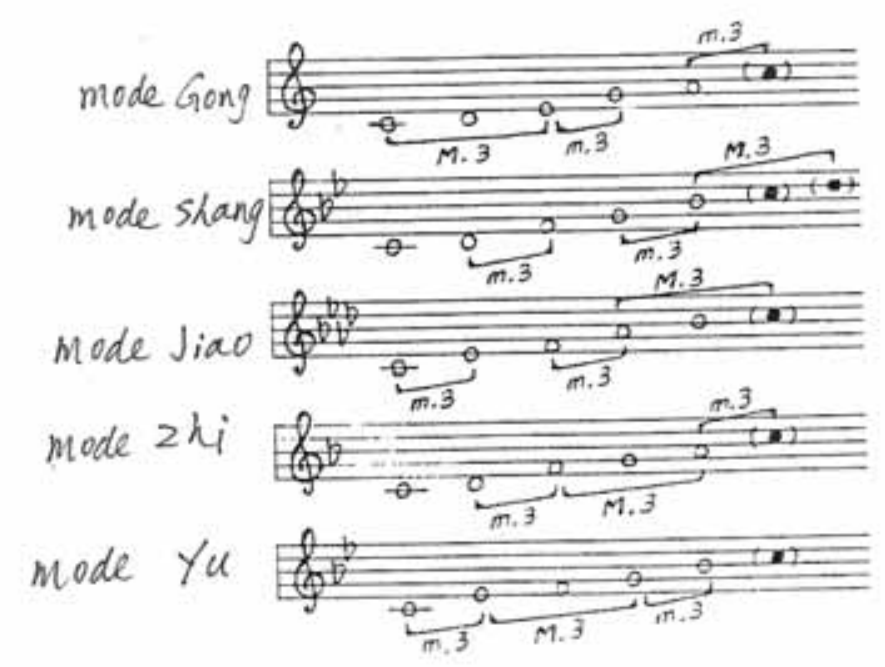

Example 1. Five pentatonic scale modes 

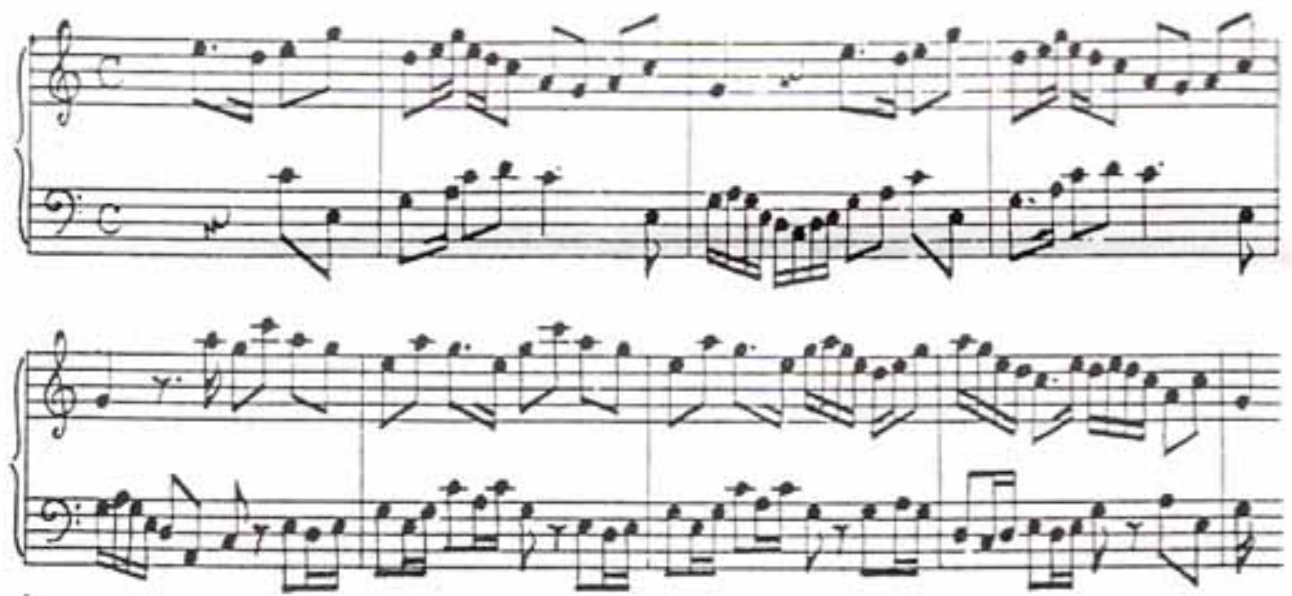

Example 2. Main theme and counter melody of Short Flute of the Shepherd Boy
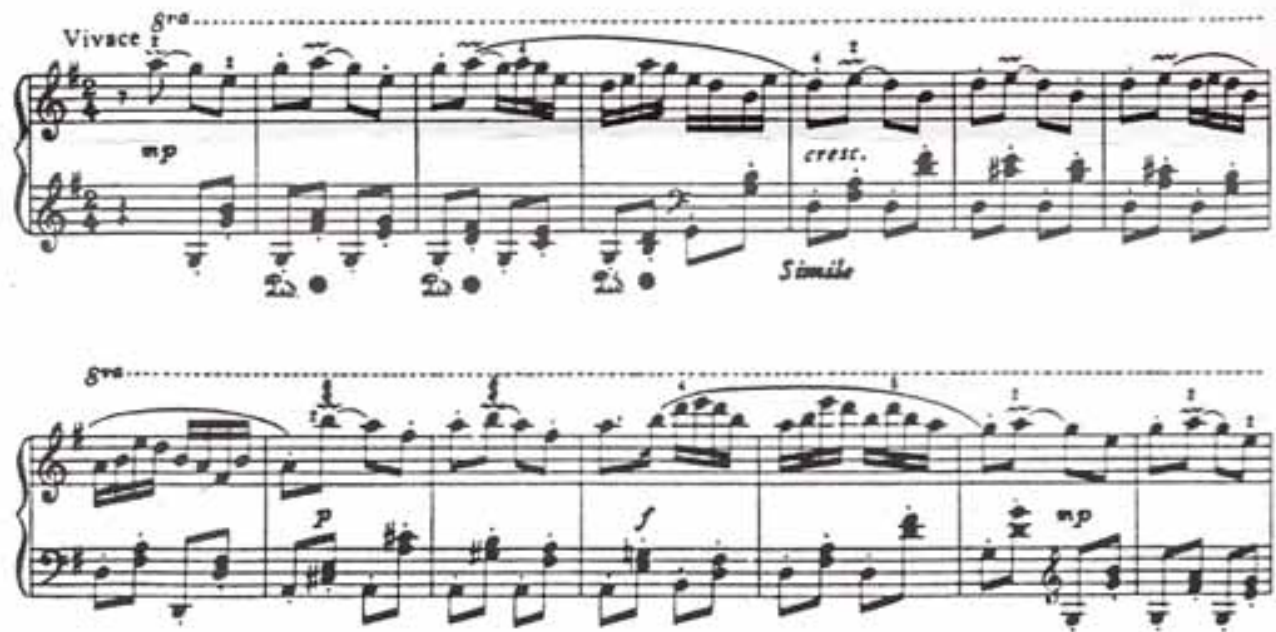

Example 3. B section of Short Flute of the Shepherd Boy

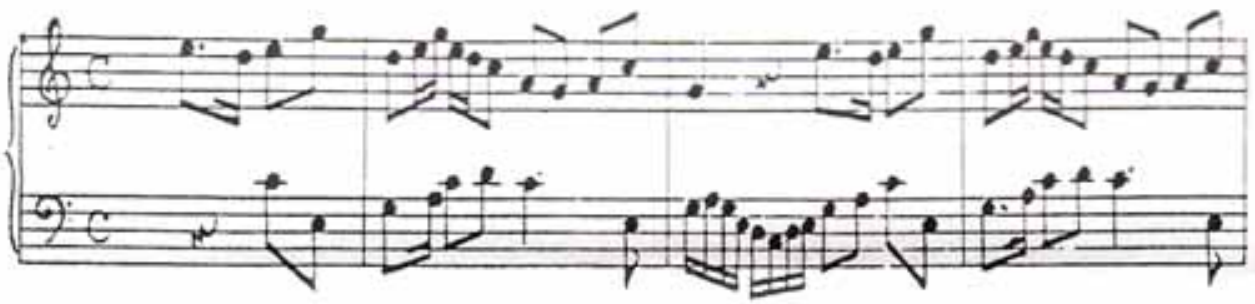

Example 4a. Original theme in Short Flute of the Shepherd Boy 


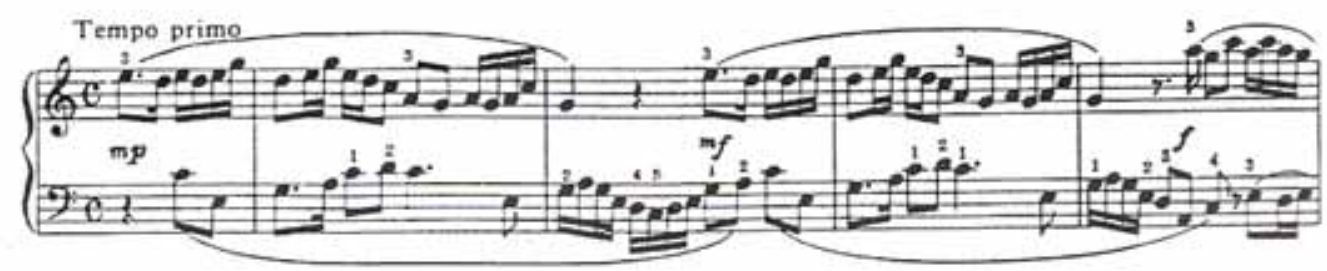

Example 4b. "JiaHua" on the theme in A section

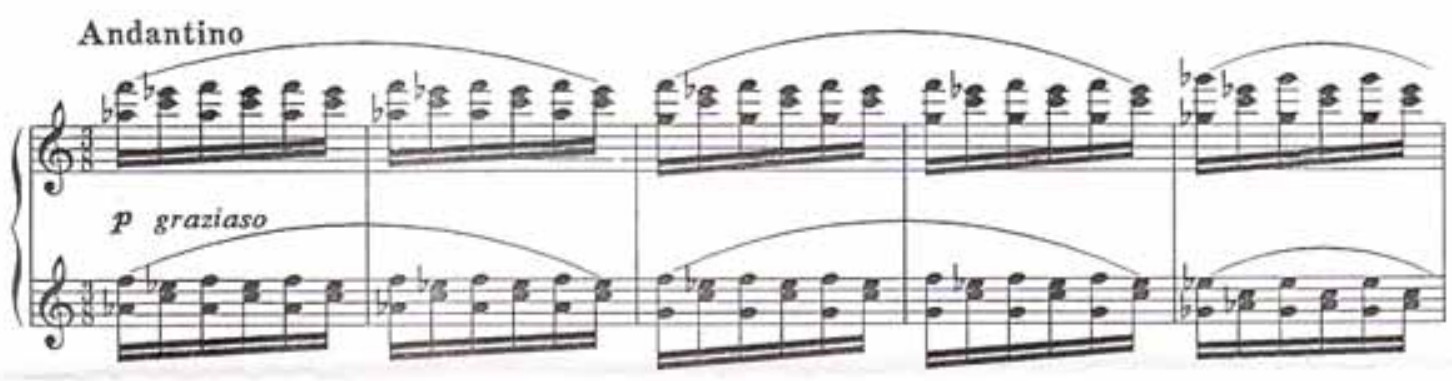

Example 5. Introduction of Seaweed Dance

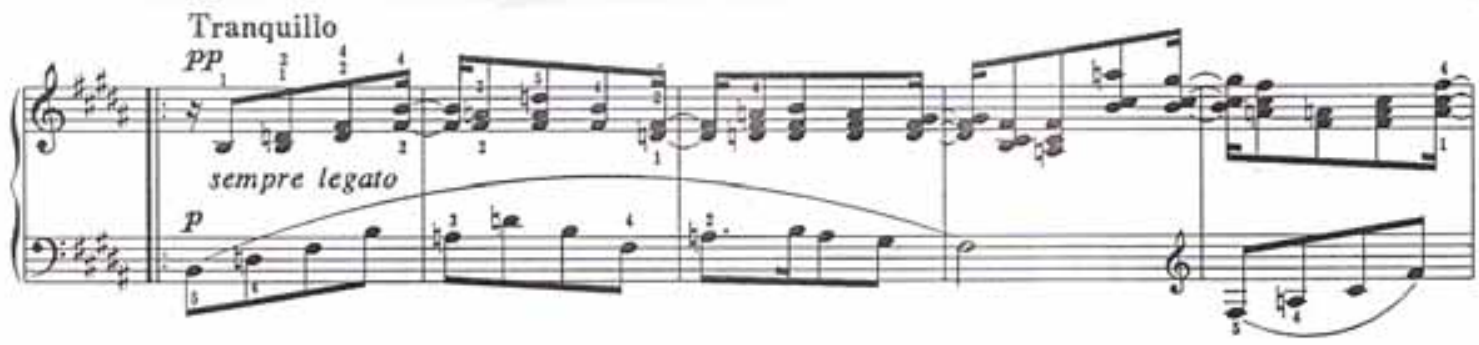

Example 6. B section of Seaweed Dance

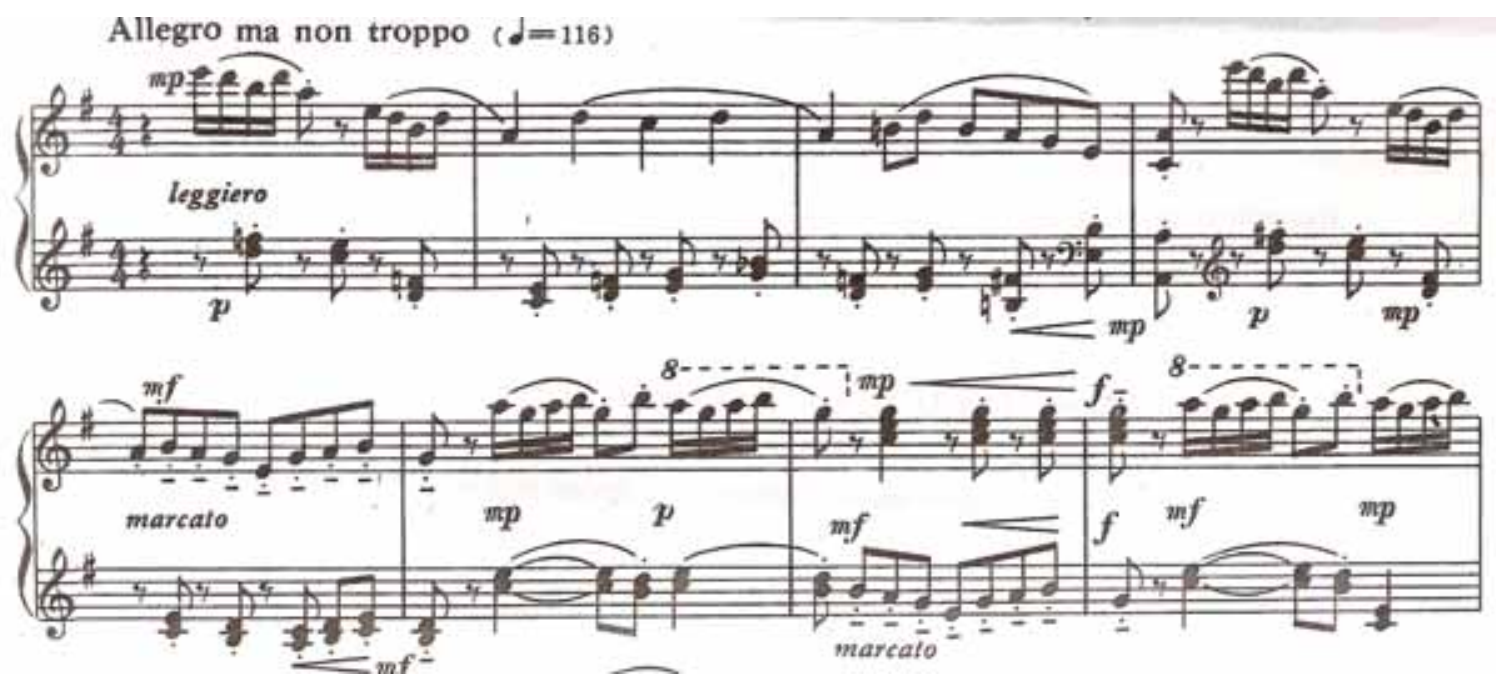

Example 7a. First theme of Twin Butterfly, from Cantonese folk tune with repetition of phrase. 


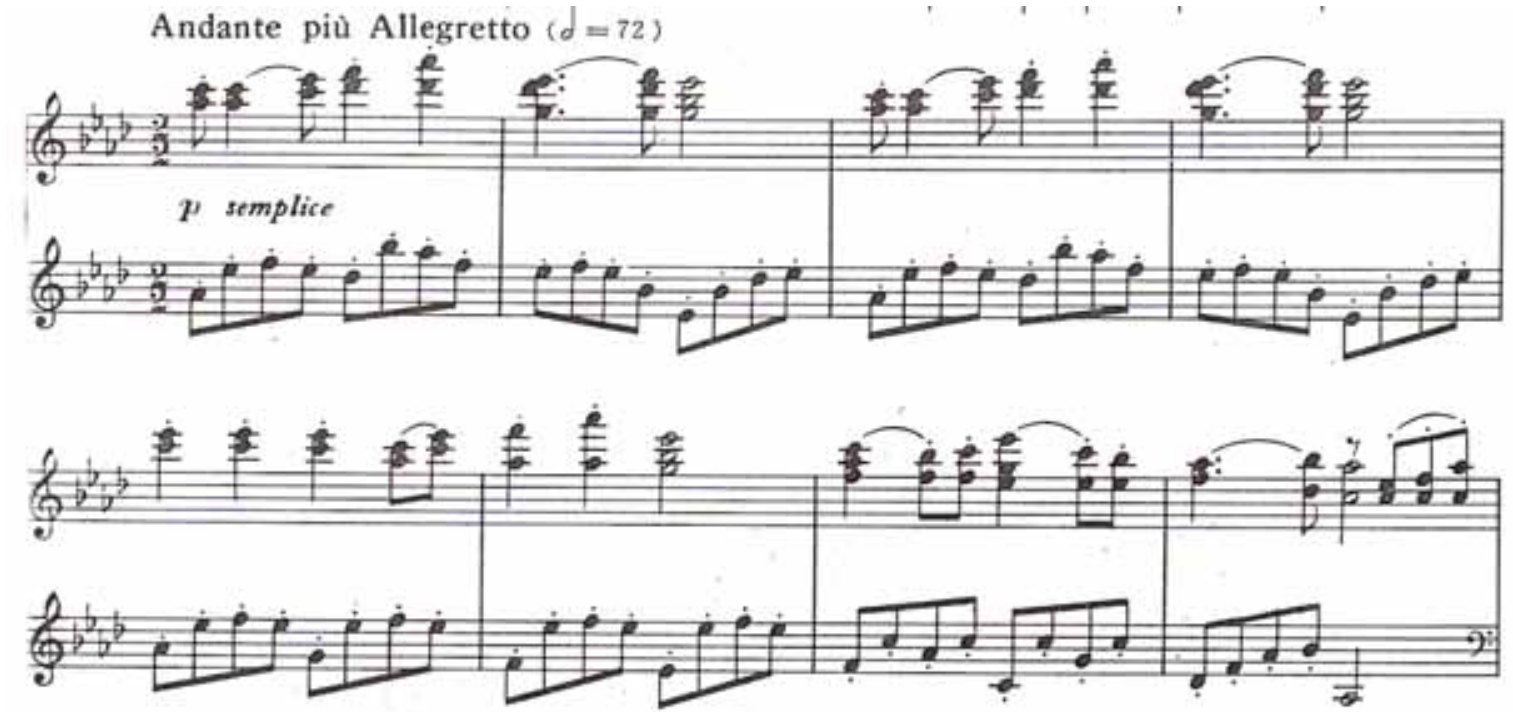

Example 7b. Second theme of Twin Butterfly, from The Narcissus

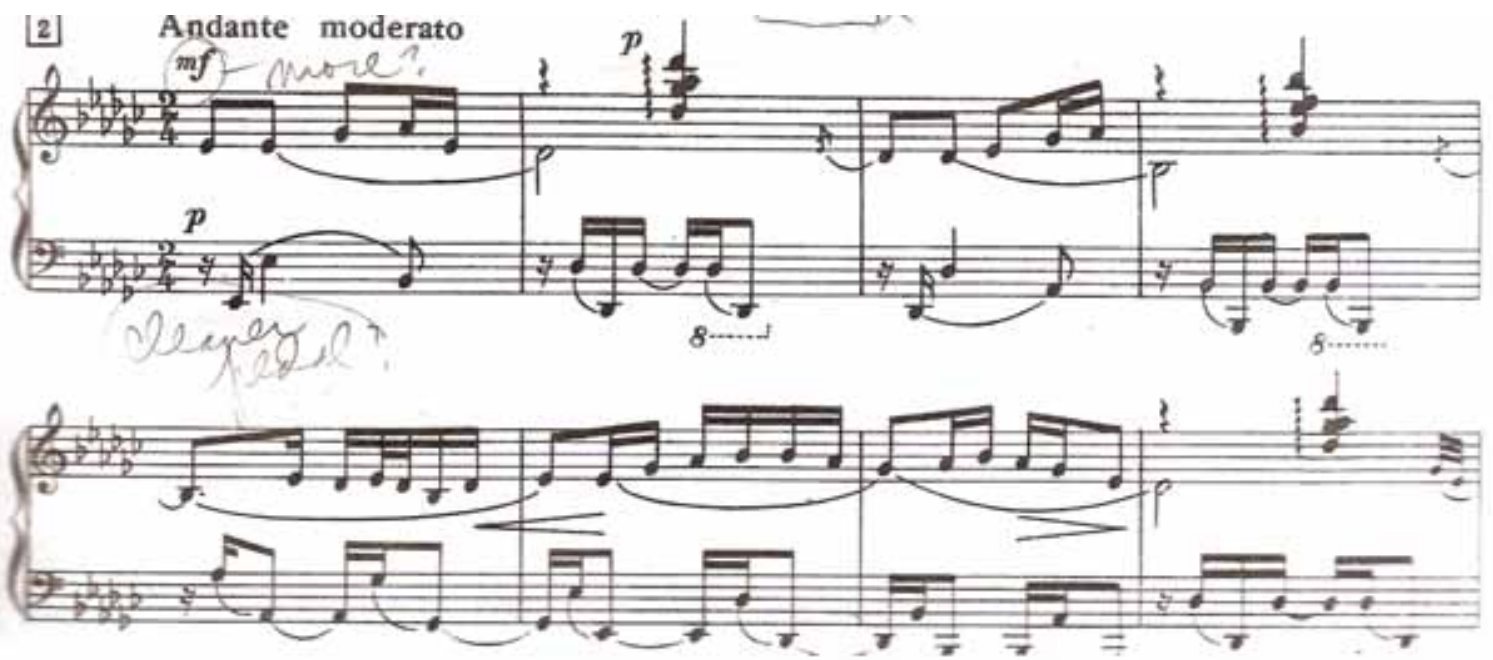

Example 8. Main theme of Xiao Gu at Sunset
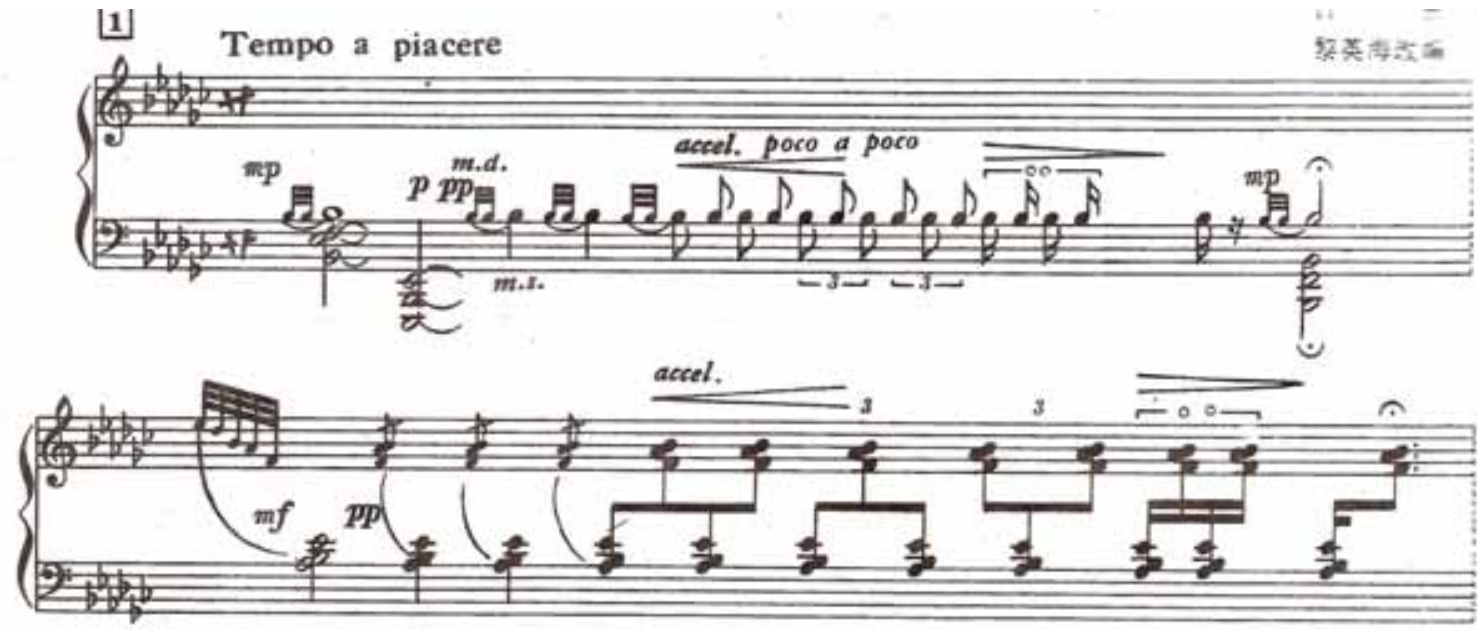

Example 9. Introduction. Imitation of Pipa and Guzheng 


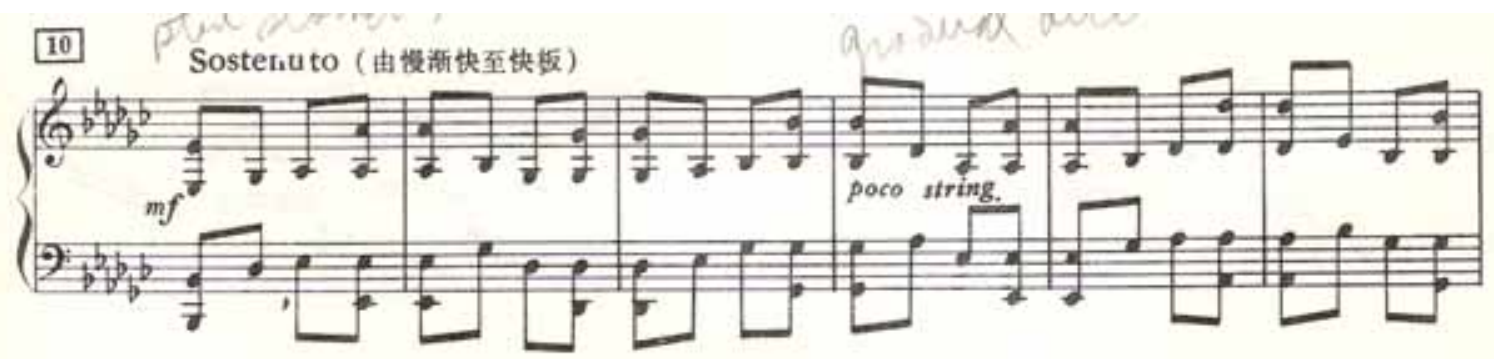

Example 10a. Tempo changes in Piu mosso-Stretto-Moderato, mm.135-148, slow-fast

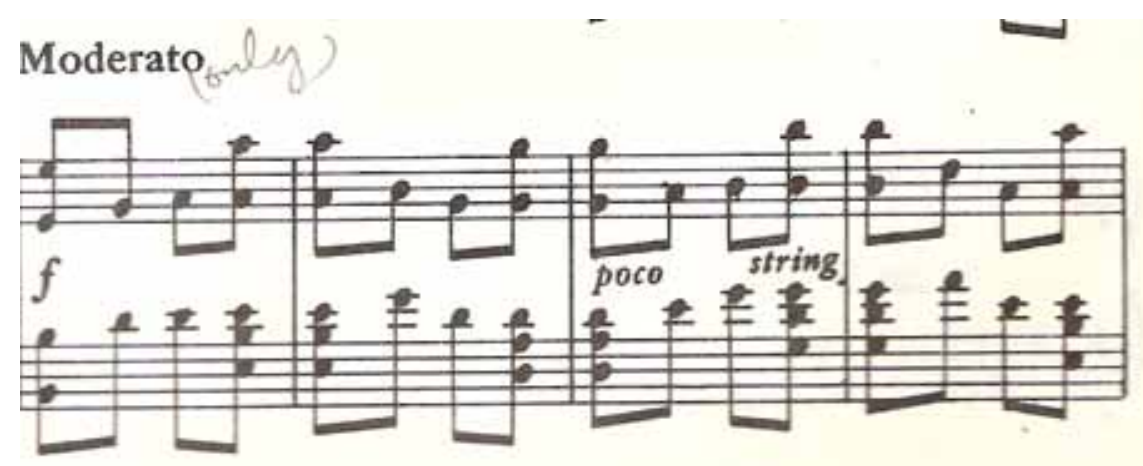

Example 10b. Tempo changes in Piu mosso-Stretto-Moderato, mm.149-157, Moderato
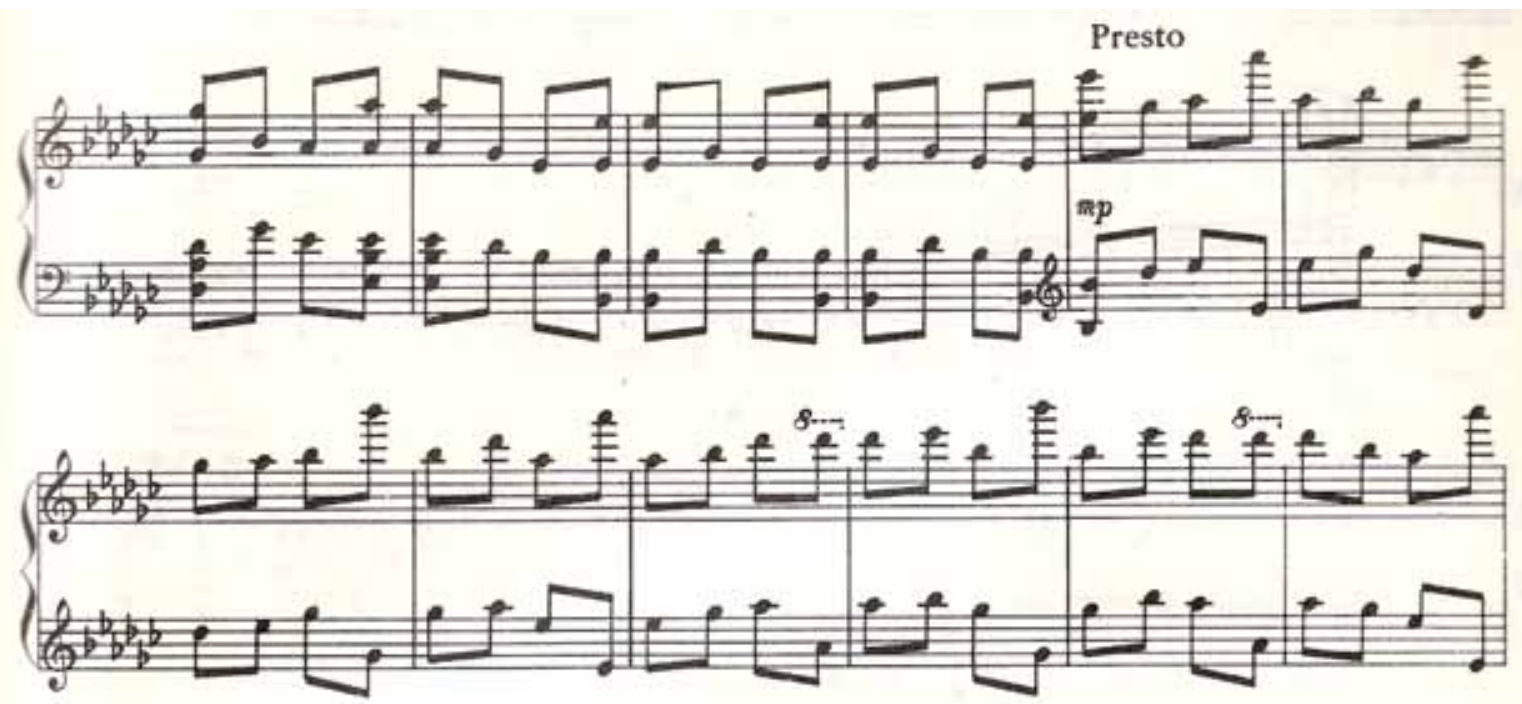

Example 10c. Tempo changes in Piu mosso-Stretto-Moderato, mm. 163-178 Presto

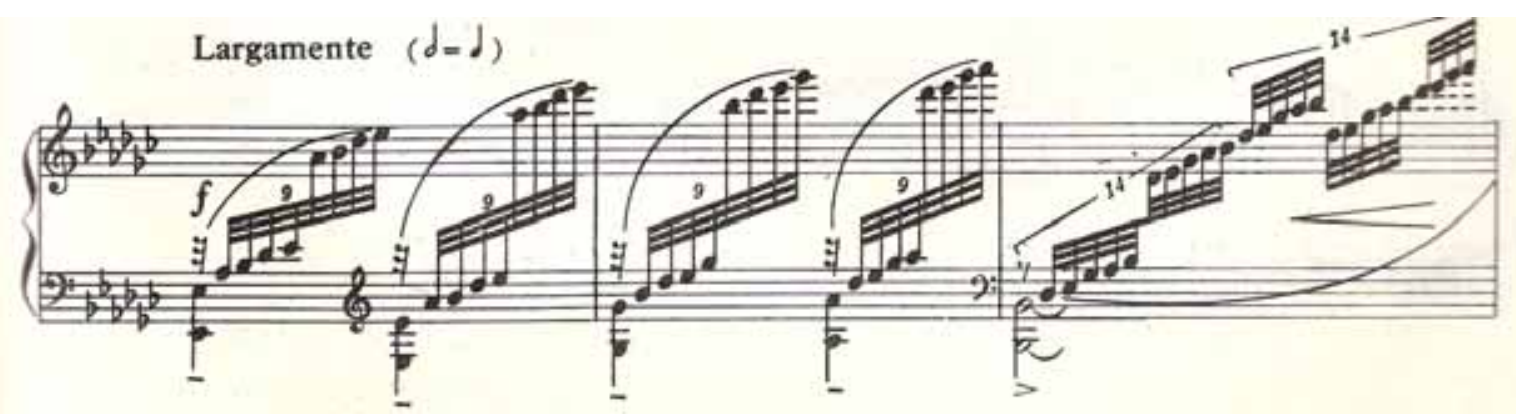



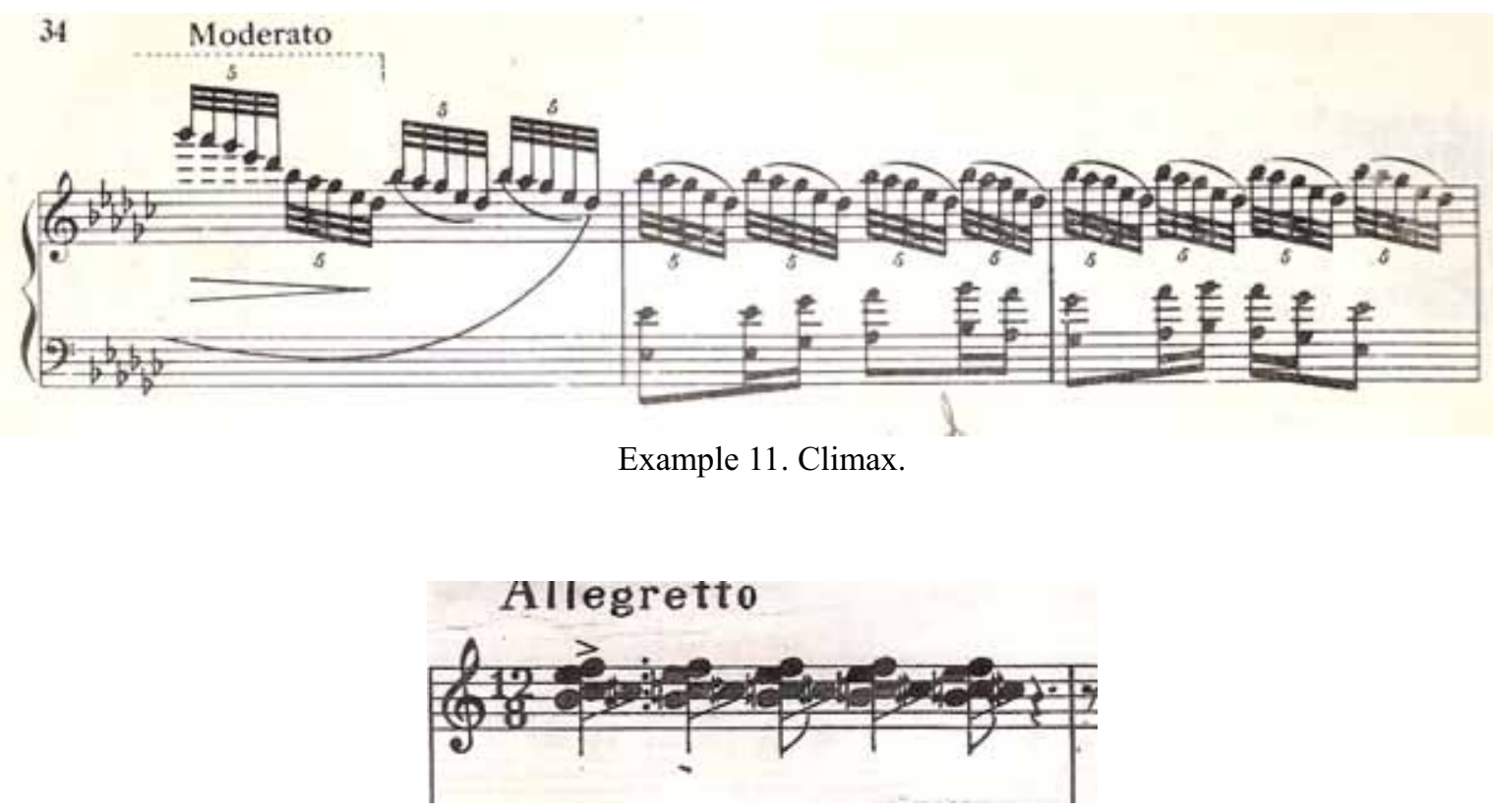

Example 12. "Grape chord"

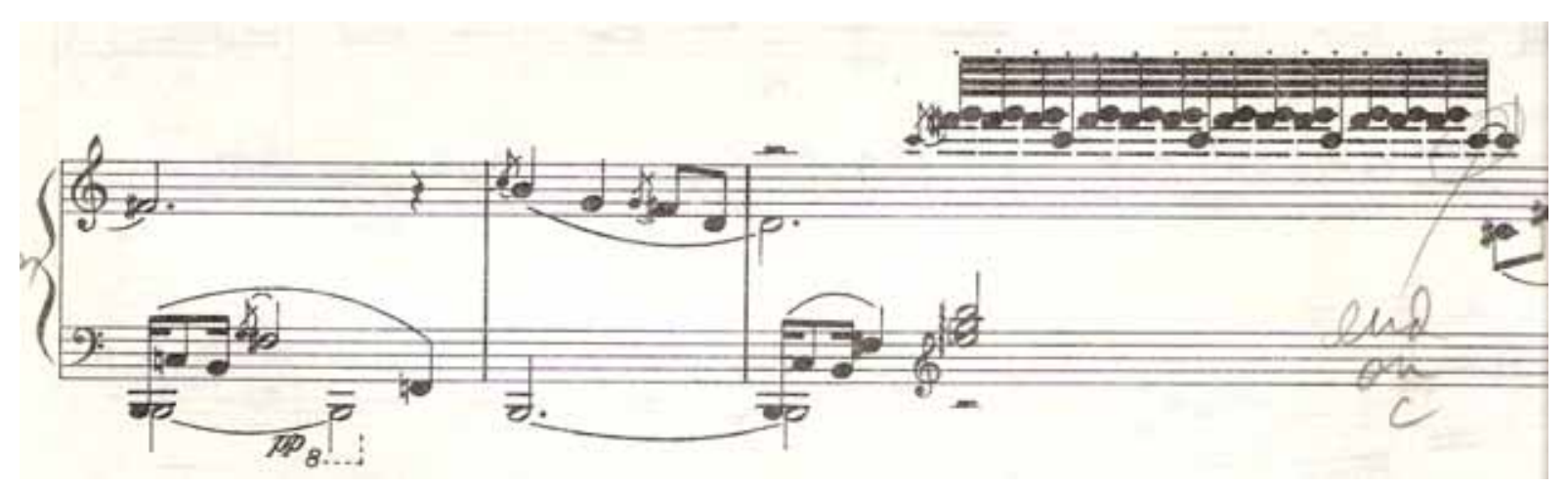

Example 13. "Grape chord" in Ostinato in bass 